\title{
Human-Computer Interaction in Intelligent Tutoring Systems
}

\author{
Ramón Toala $^{1,2}$, Dalila Durães ${ }^{1,3,4}$, Paulo Novais ${ }^{1}$ \\ ${ }^{1}$ Algoritmi Research Centre/Department of Informatics, University of Minho, Braga, Portugal \\ id7410@alunos.uminho.pt, pjon@di.uminho.pt \\ ${ }^{2}$ Technical University of Manabí, Portoviejo, Manabí Ecuador \\ ${ }^{3}$ CIICESI, ESTG, Polytechnic Institute of Porto, Felgueiras, Portugal \\ dad@estg.ipp.pt \\ ${ }^{4}$ Department of Artificial Intelligence, Technical University of Madrid, Madrid, Spain
}

\begin{abstract}
The evolution of computer science has allowed electronic devices to be introduced into education. Subsequently, a large number of computer systems were developed for the area of education, such as e-learning systems, however, computers were only used as simple support in the teaching process. Yet, due to the rapid evolution of society, citizens are constantly being pressured to obtain new skills through training. The need for qualified people has grown exponentially, which means that the resources for education/training are significantly more limited. Intelligent Tutoring Systems (ITS) aims to enable users to acquire knowledge and develop skills in a specific field. In this article, we present the student model of an ITS, in order to monitor the user's biometric behaviour and their learning style during e-learning activities. In addition, a machine learning categorization model is presented that oversees student activity during the session. Noninvasive methods will be used in the ITS, observing the interaction of users during the session. Additionally, this article highlights the main biometric behavioural variations for each activity, making these attributes enable the development of machine learning classifiers to predict users' learning preferences. The results also show that there are mechanisms that can be explored and adjusted to better understand the complex relationship between human behaviour and learning styles. These results can be instrumental in improving ITS systems in e-learning environments and predict user behaviour based on their interaction with computers or other devices.
\end{abstract}

Keywords: Intelligent Tutoring Systems, Human-Computer Interaction, Behaviour.

\section{Introduction}

ITS are learning environments that help students in the teaching-learning process. ITS implements intelligent algorithms that adapt to users and allow the application of complex learning principles. An ITS should normally work with only one user because users differ in many dimensions and the goal is to be sensitive to the idiosyncrasies of individual users. Some basic ITS activities 
should incorporate active user learning, interactivity, adaptability, and feedback.

However, we know that ITS's are complex computer programs that manage several heterogeneous types of knowledge. Thus, building such a system is therefore not an easy task. It is necessary that the team that will construct the ITS be multidisciplinary to face several problems related to the construction process. In fact, the necessary resources to build an ITS comes from various disciplines, including artificial intelligence, cognitive science, science education, human-computer interaction and software engineering. This multidisciplinary approach makes the process of building an ITS a challenging task since each researcher can have very different views of the system. Some promote the pedagogical accuracy, while others focus on effective diagnosis of the errors of the students [1].

Considering the points described so far, the objective of this paper, is to present the student model of an ITS in order to monitor the user's biometric behaviour and their learning style during e-learning activities. In addition, a machine learning categorization model is presented that oversees student activity during the session. This paper is organized as follows: section two contains the theoretical foundations; section three has the proposed architecture; section four presented the methodology applied and some results; finally, in section five the conclusions of this work are presented and some future work.

\section{Theoretical Foundations}

\section{$2.1 \quad$ ITS}

The ITS arose from the authors of the research with experience in three different disciplines: computer science (AI), psychology (cognition) and education (education and training) [2]. An ITS is a platform that incorporates AI techniques to create tutors. An ITS is an "automatic" platform, which draws courses for a person and adjusts content according to circumstances [3], [4].

Typically, the architecture of an ITS have four essential components: the specialist model, the model student, the tutor model and the interface. The domain model contains the rules for the representation of concepts, rules and problemsolving strategies. This model highlights the cognitive and affective states of the user in association with their progression as the learning process proceeds. The tutor model is the part of the ITS that designs and regulates instructional interactions with the user. This model accepts information from the student model and the domain model [4]. The student model is an overlap of the domain model. The interface is the front-end interaction with the user. This system integrates all types of information needed to interact with the user through graphics, text, multimedia, video, menus, etc [4].

The ITS consists of a system that applies the techniques of Ambient Intelligence (AmI) to better provide and support users of the educational system [5]. However, what is observed in most of these systems is that they are either adaptive or intelligent, but not adaptive and intelligent. 


\subsection{Affective Computing}

The concept of Affective Computing (AC) was introduced by Picard [6], who defined it as: "Computation that relates to, arises or deliberately influences emotions." The AC focuses on the establishment of models based on physiological and behavioural signals collected by sensors and techniques to understand, recognize, and understand human emotions and provide better feedback [7].

There are several fields in which AC can be applied: HCI; text-based communication and virtual reality; human monitoring; and education systems. In the field of HCI, the machine needs to feel and react to human emotion respectively. For example, if a person communicates with technology and is feeling frustrated or confused, technology needs to be able to respond differently to that person depending on their emotional state [8]. Thus, it is possible to build a personalized computer system with the ability to perceive, interpret the feelings of the human being, as well as giving us intelligent, sensitive and adapted responses to situations [10].

One of the problems in studying affects is the definition of what is emotion. Some research was intended to relate emotion and computer, so for Ortony, Clore and Collins [11] the identification of emotions is generally used in the field of cognitive science and has a connection to affective computing allowing computers to recognize and express emotions [6]. Many AC and HCI researchers have suggested several methods for sensing and recognizing human emotions [12], and we express our emotions in two main ways: modulation of facial expression [13] and modulation of voice intonation [14].

\subsection{Pattern Interaction using Behaviour Biometrics}

A method for obtaining a high set of data is through the use of the interactions of the keyboard and mouse. These interactions can provide a non-intrusive and easy-to-use continuous monitoring method. The behaviour of the mouse and the way we click the mouse buttons and the movement we make with the mouse changes in response to various factors, such as stress and health status [15], 16]. Based on the keystroke typing patterns and the mouse movement pattern, the researchers also observed a certain inherent variation in the typing pattern of an individual [16].

Mouse and keyboard tracking are techniques that are also used to measure and rank attention. These techniques have already been used to measure other variables, such as stress [17] and mental fatigue [18], [19]. These techniques are a non-invasive approach because the captured data is made by software running in the background and the user does not have the perception that it is being monitored. This is an advantage over other approaches because users have no idea that they are being supervised and do not change their default behaviour.

\subsection{Attention and Learning Styles}

Attention means concentration on one of the various subjects or objects that can capture our minds to the detriment of others [19]. Thus, the concept of attention can also be defined as the change of a huge set of unstructured data acquired in structured data, where the main information is preserved. 


\section{$3 \quad$ Architecture}

Based on the information provided in section two, the idea is to create an ITS system tailored to each user. In this subsection, we present the architecture of the ITS student model. For this model, it was necessary to define the following parameters: attention levels, learning style, user behaviour style and emotional state. After these defined parameters, the student model of the ITS should adjust and adapt the level of learning difficulty to each user, depending on their parameters. Thus, it was necessary to develop a new architecture due to the void found in the literature review, since most of the systems developed to date are invasive and intrusive. The idea of creating a nonintrusive and non-invasive approach based on the observation of behavioural changes of an individual or a group in relation to the behavioural and emotional pattern emerged.

The structure of the developed system is shown in Figure 1. The framework is based on the traditional ITS, with the four main modules: the expert model, the tutor model, the student model, and the interface. The student model is subdivided into two submodules: the student style and the state of knowledge. The submodule student style is where all information about the level of attention, learning style and emotional state are classified and stored. The submodule state of knowledge is received all the information from the interface, update the state updater and based on the current state of knowledge, the learning style, the level of attention and the emotional state, provide and adapt the system for the user in order to improve the learning process.

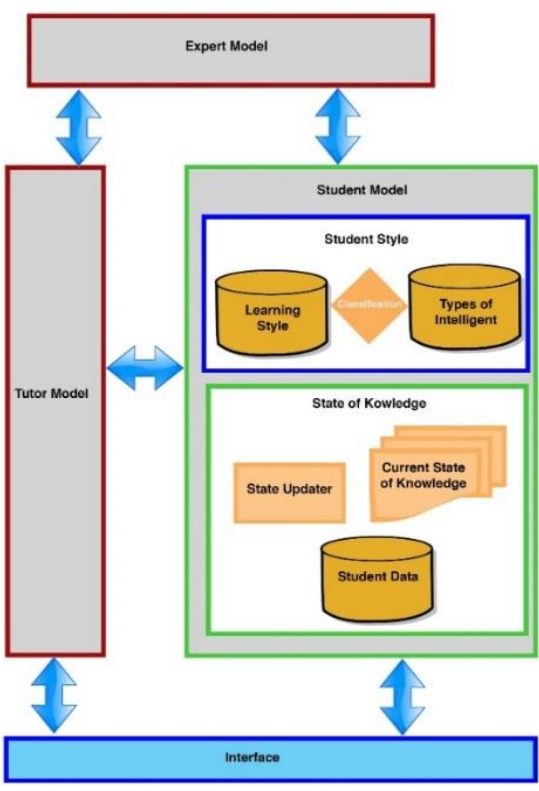

Fig. 1. Main modules of an ITS [16]. 


\section{$4 \quad$ Methodology and Results}

In this work, the approach followed is based on the dynamics of the mouse and the keys, in an attempt to propose a completely non-intrusive method to evaluate the human-computer interaction. For this study, professional students were selected to participate as they are students who easily give up activities and therefore require further monitoring.

\subsection{Population}

The study was carried out at High School of Caldas das Taipas, where evaluation activities are carried out in the computer. Each computer has a keyboard, a mouse, and a screen. The assessment activity starts at the same time for all students and they $\log$ in to the default software using their personal credentials and the activity begins. The experiment took place in four different lessons, each lasting 100 minutes. In each lesson, different learning styles were applied to the same content.

The first lesson used video exercises with step-by-step instructions. The second lesson used exercises with pictures, where the students would have to arrive at this information. The third lesson, used exercises with only text, without any supporting image. Finally, the fourth lesson used exercises with indications only audio. For this purpose, a group of 14 students were selected to carry out this experiment. Information on the four lessons is presented in Table 1.

Table 1. Summary of the characteristics of each assess activity.

\begin{tabular}{ccccc}
\hline & & \multicolumn{3}{c}{ Duration (minutes) } \\
\cline { 3 - 5 } Class & Date & $x$ & $\tilde{x}$ & $S$ \\
\hline Video & $21-05-2018$ & $7.31612 \mathrm{E}+15$ & $8.4653 \mathrm{E}+15$ & $3.00389 \mathrm{E}+15$ \\
\hline Image & $24-05-2018$ & $9.99167 \mathrm{E}+15$ & $1.21798 \mathrm{E}+16$ & $4.7135 \mathrm{E}+15$ \\
\hline Text & $25-05-2018$ & $6.19021 \mathrm{E}+15$ & $7.29301 \mathrm{E}+15$ & $2.64201 \mathrm{E}+15$ \\
\hline Audio & $29-05-2018$ & $7.0459 \mathrm{E}+15$ & $8.95808 \mathrm{E}+15$ & $3.55391 \mathrm{E}+15$ \\
\hline
\end{tabular}

can conclude that: (a) the best level of attention was obtained in the video lesson, which was the preferred learning

\subsection{Dataset}

After completing the four lessons with different learning styles, a small questionnaire was applied to students to indicate their preferred learning style. The result indicated: for $70 \%$ for the image and $30 \%$ for the video. Considering these results, considering the results obtained in the evaluation of the exercises performed in the four lessons, in the data presented in Table 2 and in Figure 2 we style of only $30 \%$ of the students. In the students' preferred style, students had a level of attention of 91.36, which has a lowest average. (b) In the case of mouse speed, the highest level was obtained in the video and image lesson. 
Table 2. Summary of the biometric features variation for each lesson.

\begin{tabular}{|c|c|c|c|c|c|c|c|c|}
\hline $\begin{array}{l}\text { Class } \\
\text { Units }\end{array}$ & $\begin{array}{l}\mathrm{CD} \\
\mathrm{ms}\end{array}$ & $\begin{array}{c}\mathrm{DBC} \\
\mathrm{px}\end{array}$ & $\begin{array}{c}\mathrm{DDC} \\
\mathrm{px}\end{array}$ & $\begin{array}{cc}\text { DPLBC } & \text { KDT } \\
\mathrm{ms} & \mathrm{px}\end{array}$ & $\begin{array}{c}\mathrm{MA} \\
\mathrm{px} / \mathrm{s}^{2}\end{array}$ & $\begin{array}{c}\mathrm{MV} \\
\mathrm{px} / \mathrm{ms}\end{array}$ & $\begin{array}{c}\text { APP } \\
\%\end{array}$ & $\begin{array}{c}\text { TBK } \\
\mathrm{ms}\end{array}$ \\
\hline Video & 188.31 & 206.1 & 214.24 & 2819.121002 .8 & 0.6811 & 0.5931 & 94.14 & 1865 \\
\hline Image & 150.73 & 150.73 & 161.88 & 3725.352669 .1 & 0.6659 & 0.5413 & 91.36 & 1738 \\
\hline Text & 146.43 & 227.4 & 152.52 & 2838.141223 .0 & 0.6056 & 0.5312 & 89.23 & 1073.1 \\
\hline Audio & 281.0 & 189.2 & 119.10 & 2408.52714 .1 & 0.5828 & 0.4986 & 93.7 & 1758 \\
\hline $\bar{x}$ & 187.66 & 227.0 & 165.70 & 2946.411384 .2 & 0.6367 & 0.5447 & 92.08 & 1599.3 \\
\hline
\end{tabular}
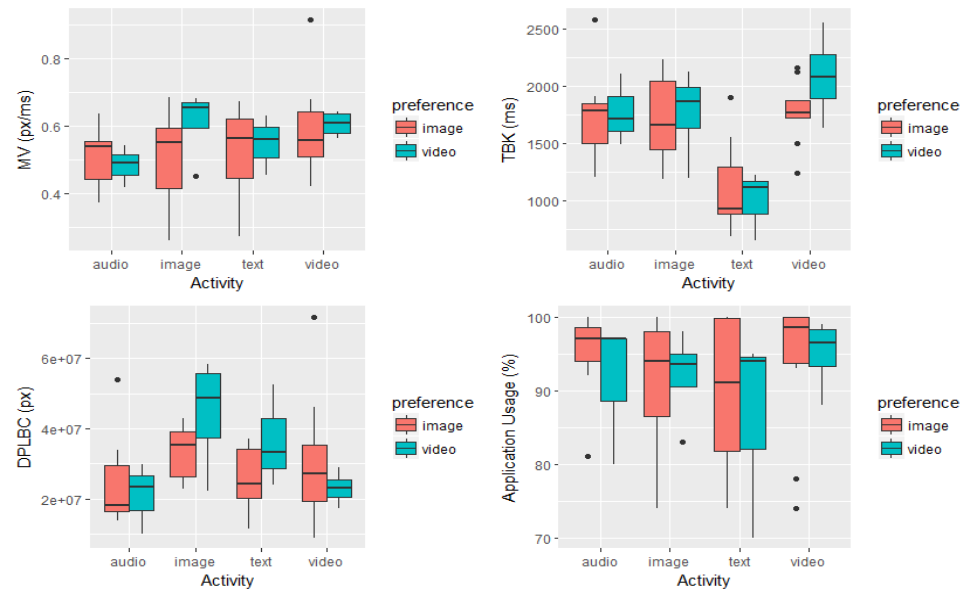

Fig. 2. Activity for the four lessons.

\section{Conclusion and Future Work}

This paper only presents the first model of an ITS system. A noninvasive and non-intrusive approach to an ITS is proposed based on biometric analysis of work behaviour in different classes with different learning styles. The system monitors and analyzes the dynamics of the mouse, a dynamic keyboard and tasks to determine student performance.

The results show that it is still possible to improve some mechanisms to better understand the complex relationship between human behaviour, attention and evaluation. Better learning strategies for each user can also be implemented.

These results are crucial to improving learning systems in an e-learning environment and predicting student behaviour based on their interaction with technology devices.

Briefly, it was verified that the main characteristics to be analyzed to obtain a prediction about the student, concentrate on the Key Down Time, Mouse Velocity, and Distance Point between Clicks (DPLBC). However, since the preferences indicated by the students were only of the "video" and "image" activities, it is necessary to make new case studies to better complement the other activities ("audio" and "text"). Increasing the num- 
ber of cases to be applied in the learning process, the greater the validation of the future forecast model.

As future work, still in the development of the student model, the research will be focused on: (a) increasing the number of case studies available for analysis; (b) increase the number of quality resources that would allow better monitoring of the student's attention per- formance; (c) detailed analysis of characteristics that influence student performance (for example, by correlating students' final grades with biometric behaviors); and (d) definition of different student profiles to improve the platform's adaptive learning mechanisms. In addition, it is necessary to develop other models to obtain complete ITS.

\section{Acknowledge}

This work has been supported by FCT - Fundação para a Ciência e Tecnologia within the Project Scope: UID/CEC/00319/2019.

\section{References}

1. O'Donnell, E., Lawless, S., Sharp, M., \& Wade, V. P. (2015). A review of personalised elearning: Towards supporting learner diversity. International Journal of Distance Education Technologies (IJDET), 13(1), 22-47.

2. Cataldi, Z., \& Lage, F. J. (2009). Sistemas tutores inteligentes orientados a la enseñanza para la comprensión. Edutec. Revista Electrónica de Tecnología Educativa, 0(28), 108. https://doi.org/10.21556/edutec.2009.28.456.

3. Paviotti, G., Rossi, P. G., \& Zarka, D. (2012). Intelligent tutoring systems: an overview. Pensa Multimedia.

4. Ahuja, N. J., \& Sille, R. (2013). A critical review of development of intelligent tutoring systems: Retrospect, present and prospect. International Journal of Computer Science Issues (IJCSI), 10(4), 39.

5. P. Brusilovsky and C. Peylo, Adaptive and Intelligent Webbased Educational Systems, Int. J. Artif. Intell. Ed. 13(2-4), (2003), 159-172, ISSN 1560-4292. http://dl.acm.org/citation. $\mathrm{cfm} ? \mathrm{id}=1434845.1434847$.

6. Picard, R. (1997). Affective Computing. MIT Press.

7. Lee, H., Choi, Y., Lee, S., \& Park, I. (2012). Towards Unobtrusive Emotion Recognition for Affective Social Communication. The 9th Annual IEEE Consumer Communications and Networking Conference - Special Session Affective Computing for Future Consumer Electronics. Las Vegas, NV, USA : IEEE.

8. Pang, B., \& Lee, L. (2006). Opinion Mining and Sentiment Analysis. Foundations and Trends ${ }^{\circledR}$ in Information Retrieval, 1(2), 91-231.

9. Picard, R., Papert, S., Bender, W., \& Blumberg, B. (2004). Affective learning - a manifesto. BT Technology Journal 22(4), 253-268.

10. Ortony, A., Clore, G., \& Collins, A. (1990). The cognitive structure of emotions. Cambridge Press.

11. Rincon, J., Costa, A., Villarrubia, G., Julian, V., \& Carrascosa, C. (2018). Introducing dynamism in emotional agent societies. Neurocomputing, (272), 27-39.

12. Ekman, P. (1992). An argument for basic emotions. Cognition \& emotion, 6(3-4), 169200. 
13. Banse, R., \& Sherer, K. (1996). Acoustic profiles in vocal emotion expression. Journal of Personality and Social Psychology, 70 (3), 614-636.

14. Monrose, F., \& Rubin, A. (2000). Keystroke dynamics as a biometric for authentication. Future Generation Computer Systems, 16(4):351-359.

15. Araújo, L. C., Sucupira, L. H., Lizarraga, M. G., Ling, L. L., \& Yabu-Uti, J. B. (2005). User authentication through typing biometrics features. IEEE transactions on signal processing, 53(2):851-855.

16. Carneiro, D., Novais, P., Pêgo, J., Sousa, N., \& Neves, J. (2015). Using Mouse Dynamics to Assess During Online Exams . Hybrid Artificial Intelligent Systems, vol. 9121, 345356.

17. Pimenta, A., Gonçalves, S., Carneiro, D., Riverola, F., \& Novais, P. 2015. Mental Workload Management as a Tool in e-Learning Scenarios. In B-Peces, O. Paillet, \& A. Ahrens, Proceedings of the 5th International Conference on Pervasive and Embedded Computing and Communication Systems (pp. 25-32). Scitepress.

18. Pimenta, A., Gonçalves, S., Carneiro, D., Fde-Riverola, F., Neves, J., \& Novais, P. (2015). Mental workload management as a tool in e-learning scenarios. 2016 International Conference on Pervasive and Embedded Computing and Communication Systems (PECCS) pp. 25-32). IEEE.

19. Mancas, M. (2015, October 6). Attention in computer science - Part 1. Retrieved December 31, 2016, from News and insights from EAI community - Blog: http://blog.eai.eu/attention-in-computer-science-part-1/.

20. Andrade F., Novais P., Carneiro D., Zeleznikow J., Neves J. (2010) Using BATNAs and WATNAs in Online Dispute Resolution. In: Nakakoji K., Murakami Y., McCready E. (eds) New Frontiers in Artificial Intelligence. JSAI-isAI 2009. Lecture Notes in Computer Science, vol 6284. Springer, http://dx.doi.org/10.1007/978-3-642-14888-0_2.

21. Rodrigues M., Novais P., Santos M. (2005), Future Challenges in Intelligent Tutoring Systems - Famework, Recent Research Developments in Learning Technologies: Proceedings of the 3rd International Conference on multimedia and Information \& Communication Technologies in Education, A. Méndez Villas, B. Gonzalez Pereira, J. Mesa González, J.A. Mesa González (Eds), Publishers Formatex, pp 929-934. 